\title{
Kamishibai educational: a tool as a common project
}

\section{Kamishibai educativo: una herramienta como proyecto común}

\author{
CASTRO-FLORES, Verónica Azucena †*
}

Sistema Estatal de Telesecundarias

ID $1^{\text {st }}$ Author: Verónica Azucena, Castro Flores / ORC ID: 0000-0002-6165-1793

DOI: $10.35429 / J E H .2019 .4 .3 .26 .32$

Received January 29, 2019; Accepted June 21, 2019

\begin{abstract}
The creation of the collaborative team for the distinction of improvements in activities designed to impact teaching strategies, which will ultimately provide an increase in literacy, historical research and creativity for the acquisition of new knowledge through tools for planning, reading of discontinuous texts, and the visual expression of specific texts that give meaning to the systematization of processes that can be reproduced in different areas of knowledge of expected learning but with the constructivist approach to education delineated by the concept of General Systems Theory and the emphasis on humanism as a regulator of the emotions of human beings that intertwine in an educational community.
\end{abstract}

Systematization, Processes, Constructionism, Literacy, Strategies

\section{Resumen}

La creación del equipo colaborativo para la distinción de mejoras en las actividades destinadas a impactar las estrategias de enseñanza, lo que en última instancia proporcionará un aumento de la alfabetización, la investigación histórica y la creatividad para la adquisición de nuevos conocimientos a través de herramientas de planificación, lectura de textos discontinuos, y la expresión visual de textos específicos que dan sentido a la sistematización de procesos que pueden ser reproducidos en diferentes áreas de conocimiento del aprendizaje esperado pero con el constructivista enfoque de la educación delineado por el concepto de Teoría General de Los Sistemas y el énfasis en el humanismo como regulador de las emociones de los seres humanos que se entrelazan en una comunidad educativa.

Sistematización, Procesos, Construcción, Alfabetización, Estrategias

Citation: CASTRO-FLORES, Verónica Azucena. Kamishibai educational: a tool as a common project. Journal-Economic History. 2019. 3-4: 26-32.

\footnotetext{
* Correspondence to Author (email: veronicacastro1352@ @otmail.com)

$\dagger$ Researcher contributing as first author
} 


\section{Introduction}

In the constant search for integral effectiveness, management is to carry out an initiative or project according to the RAE (2019), where it must be inferred that all those who affect a specific area must acquire a commitment, together to direct their " self-improvement and continuous improvement "in Chiavenato 2002, cited in López (2005), that is why the activities that were visualized were from an approach like the one proposed by Schmelkes (2001)“... identify improvement as a permanent, slow and gradual process " that inspires the managers, teachers, students, parents and educational authorities that underlie the schools in the school zone no. 10 of the State Telesecundaria System based in Canatlán, Dgo., To act accordingly to the discovery of the problems identified in each educational establishment.

Training of the educational agents was combined, the strategies and culture of the teachers who have been in the school contextual geography were rescued, the characteristics of the students and functionality of the physical, environmental and distinctive structures of each school were included. it implied a shared action, a social act of teacher involvement, as well as the proposal of the Kamishibai educational tool to unite education professionals in the universe of the school zone around social realities, to relearn within teaching.

Reading as a trigger for the social practices of language within the classroom, generated in teachers the recognition that it cannot be separated from writing, speech and active listening; but in that interaction they are resigned to being interpreted by students from texts with particular characteristics that have a specific sociocultural background and from unique personal experiences that are also affected by conventions related to the same text, so that each gender, type or Textual format implies not only a different approach, but also the mobilization of different conceptual, procedural and attitudinal knowledge that can be taught and developed throughout the student's school life from the teaching intervention cited in Strategy to increase and strengthen the reading ability
The following are some elements, cited in SEP (2015) that were considered at the time of designing and implementing the reading strategy that would also address literacy and that would respond to the needs of students:

- Contemplate reading on the various crosscutting themes of the curriculum, as well as the integration into the subjects as a priority objective.

- Develop and increase the literacy skills of teachers.

- Verify the availability of a sufficient bibliographic collection relevant to the age and interests of the students, weighing the existence of expository texts related to the different areas or subjects of the curriculum.

- Consider the uses of reading within the classroom (development of reading habits, development of language skills, development of reflective and critical thinking, improvement of communication skills, access to culture, learning of concepts, improvement of grammar rules, vocabulary enrichment, socialization) and, based on this, define the objective of each activity.

- Identify the motivations that encourage - or discourage - students to read.

- Provide reading experiences that help improve efficiency and reading comprehension autonomously.

- Accompany young people during the reading process by helping them to activate previous knowledge, establish relationships between content and use reading and learning strategies that are most relevant to them.

- Consider and attend to the different learning rhythms.

- Encourage the development of functional learning through reading. 
Focusing actions by recovering the above and from the following specific functions of school supervision taken from SEP (2014) "Promotes collaborative work between schools in the area, Promotes and models the appropriate use of available educational materials and tools, in addition to that brings new materials to the teaching groups that enrich their function, manages external technical-professional support for teachers "so that they could have the appropriate processes in each of the stages of project development, the skills of the teachers to include their daily work and taste, in addition to help to address academic issues and content that aims to reach the expected learning of the different subjects.

\section{Method description}

Description of the method The method used was action research cited by Vidal \& Rivera (2007), it is said that it is a positioning of interrelation between praxis and theoretical support, trying here and now a method with the modification steps to configure changes in the contextual environment of its use, it was also visualized as something conducive to the academic area where the processes are cyclical, where the projection of what is intended to be done with how and with what they are appropriate, with the detailed record of what happens in the classrooms and the punctual introspection of the teachers, so that at the time of carrying out the phenomenon applied regularly, they could configure options to solve the problems that were discovered, deepened and located in the educational reality.

Stenhouse cited in Vidal \& Rivera (2007) said that the immediacy in the reorientation of education and that the inquiry from the scientific method generated the occupation, contribution and creativity of the student, in the case of the action was responsible for giving the support theoretical to boost the human being. To demystify that theory and practice are dissociated by nature, networks are projected in which the unique essence of going from research to action is created from within, refeeding at the time of examining the fact and returning to genesis, to be and look like a solid structure of the scientific method with oriented movement.
The instruments that were used to gather information, monitor and evaluate were validated instruments that configure the teaching actions and the impact on the learning of the students that are regularly used by the school supervisors, since they allow to have a part of the whole, from the generic control and monitoring function that can be found described in the effective supervision notebook that supports the professionalization of school supervisors (SEP, 2014), which describes the permanent action of verifying the level of achievement achieved through the delimitation of current regulations, by public policies, from the perspective of effective teaching intervention.

\section{Planning was designed from:}

Contextual diagnosis of the school zone prepared since the beginning of the school year, the second week of October to have a location in time, in addition the concentrate of:

a) Of supervision sheets.

b) Visiting Diary.

c) Statistics from previous 3 years and the current one.

d) Academic diagnoses (internal and external).

e) SisAT Results.

The problems of:

- Lack of systematization of the didactic strategies that take place in the classrooms focused on the resolution of a problem.

- $\quad$ Spacing in strategies designed for reading and writing.

- establish an accompaniment to influence in a timely manner as part of the solution and not the problem.

- The elaboration of planning from an integral context of the assessment of the students.

Michael Foucault (1992) quoted in Urraco, M. and Nogales G (2013), "discipline manufactures an individuality" because he perceived that everything that surrounds the individual is always generated from badges with clear signs that reflect the construction of each One of the people who make up a society.

CASTRO-FLORES, Verónica Azucena. Kamishibai educational: a tool as a common project. JournalEconomic History. 2019 
That is why the formulation of objectives synthesized the tangible part of instruments that concentrate the identity of the students from the surrounding context, for which it was identified in the diagnosis, with the intention of including a direct action on what was found in the school zone, in addition to impacting from the theoretical foundation of why addressing a situation of real and very relevant.

It is significant that it is centered that for the present proposal, the system will be related to what is quoted in Lara (1990) and Samoura (1999) within De la Peña, G and Velázquez, R. (2018) which merge relevant aspects, which allowed a convergent action of components that meet: each teacher in the school zone are interconnected by identity and belonging, so when one of them acquires a certain behavior everything is necessarily modified and in turn the common action will depend on at least one teacher To impact the entire school zone, this analogy allowed: to identify the degree of reflection on the teaching practice by identifying problems and actions carried out from each school in the area connecting from the similarities, developing strategies shared by a technical team external to the school and school supervision that drive motivation towards the object of learning, but only as mediators, because $\mathrm{p}$ To impact on the appropriation of strategies, the teacher will have the original impulse if there were changes in the area after another teacher after the initial training acquired the taste for the strategy, which for this activity will be "Kamishibai educational"

In the field of operation and organization of the school it was expected that this will promote healthy, peaceful and respectful coexistence in schools, within the framework of the development of an inclusive and open to diversity school culture that the teacher assumes a strategy to impact on the appropriation of literacy in order to systematize processes through global actions.

Place the school as a particular space to include the context itself through teacher training and strategy adaptation. Configure some of the causes to influence inclusive through the appropriation of actions from the skills of students and teachers.
It is important to quote Schmelkes, $\mathrm{S}$. (1994) when he mentions that "A movement towards quality begins when a problem is prioritized, its causes are identified and the team is mobilized to attack these causes at the root", from the reflexivity of the groups teachers in addition to the actions that have been processed by others to solve common problems, linking what underlies the visible, that is, what cannot be perceived until a thorough recognition of the facts and circumstances is made.

The approach that was made was to incorporate the technique of educational kamishibai through a systematization of processes from inclusion, equity and attention to an academic difficulty by encouraging three situations in a clear way to generate a didactic and creative space through the technique mentioned, which allows to expose the strengthening of the communicative abilities of the students through the full use of oral and written language.

The modality that was incorporated was that of educational projects suggested in the Plan and Program of Study of Mother Language, Spanish for Basic Education, the theme that was developed was: The life of Francisco Villa with the assessment of a representative character of Mexico using The narrative genre, through a dynamic of historical research that led students to begin with the teaching intervention directly and incorporating external agents achieving the combination of a series of elements such as: guide, bibliographic and work cards, it was also included it was designed a "base document" as a constructive element of a systematized vision of procedures that merge the appropriation of new knowledge, as well as the integration of grounded practice.

As cited in Schön (1983) "it is a process of reflection in the action or reflective conversation with the problematic situation, a critical and theoretical knowledge built through dialogue and interaction with colleagues and students, which gives pedagogical knowledge a more social dimension "subtly the ideas are extracted 


\section{Analysis from the regression by demand curve}

The preference towards the kamishibai educational strategy increased the consumption of the 17 schools in the school zone from facilitation, systematization, as well as by contextualization to educational practice. The training was given as follows and achievement of incorporation.

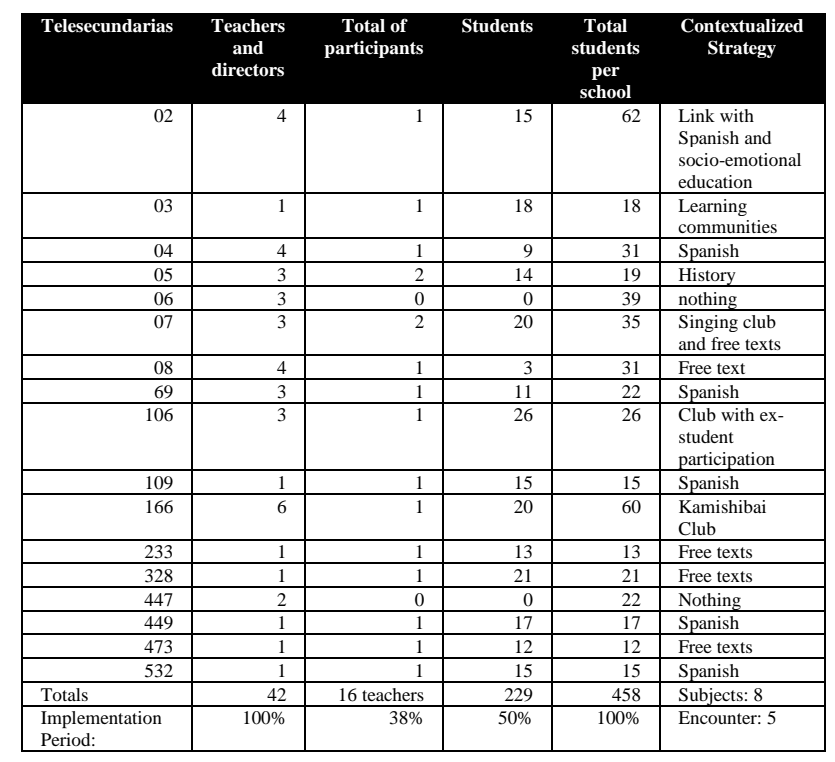

Table 1

In the 5-month period that the strategy was implemented:

\begin{tabular}{|c|c|c|c|c|}
\hline $\begin{array}{c}\text { Period } \\
\text { (months) }(x)\end{array}$ & $\begin{array}{c}\text { Demand } \\
\text { (teachers and } \\
\text { students) } \\
\text { (and) }\end{array}$ & $\mathbf{x y}$ & $x^{2}$ & $y^{2}$ \\
\hline 1 & 4 & 3 & 9 & 9 \\
\hline 2 & 7 & 16 & 64 & 256 \\
\hline 3 & 10 & 30 & 100 & 900 \\
\hline 4 & 13 & 52 & 169 & 2704 \\
\hline 5 & 16 & 75 & 225 & 5625 \\
\hline
\end{tabular}

Teachers to a greater degree of ignorance of the strategy, there was less participation of these, in the visibility of direct interaction with the materials, intertwining the different factors that converge in the situations of the educational phenomenon of which a disturbing lack of curiosity, which breaks the innovative actions that teachers can acquire to provide a better form of intervention. The increase in the demand for educational kamishibai took place gradually, to the extent that the teachers since the training appropriated the strategy: 6 teams were formed and only $17 \%$, that is, 1 single team did not present any activity. Of the 42 teachers who participated in the training, $14 \%$ did not prepare a story to present, that is, 6 teachers.
The situations that allowed the demand curve were:

a) The teaching characteristics.

b) The adaptation to the context.

c) Freedom in the chair.

d) The transversality between the subjects.

e) The formulation of a systematized strategy with well-defined characteristics that allowed flexibility in the actions that were defined, by implementing in all teachers.

\section{Results}

The quantifiable results that were obtained were determined from the development of the historical research, reading and writing of the students, the accompaniment of the teachers in an educational project with specific lines on three subjects of the curriculum of the 2017 Plan of basic education, bringing a history of students and schools with a solid foundation from the training of the figure of the supervisor, teacher and students.

It is of the utmost importance to establish that the 38 teachers who participated since the training formulated the integration to their aulic contexts, from 4 original educational intentions, but that extended to complementary work of internal, external, direct and indirect agents with diversifications, involvement and Complementation of other methodologies such as learning communities.

The characteristics of the materials used also marked the difference between the final presentations of the elaborated texts, configuring the cosmology of each one of the communities in which the 17 schools participating in the activities planned from the planning by competences are located, as well as The teaching and management profiles also marked the adequacy of the research prepared to give a methodological support in this area, as well as the sources that consulted the instances that were used to formalize the figure to which the final activity was framed. 
The creation of the collaborative team for the distinction of improvements in activities designed to impact teaching strategies, which will ultimately provide an increase in literacy, historical research and creativity for the acquisition of new knowledge through tools for planning, reading of discontinuous texts, and the visual expression of specific texts that give meaning to the systematization of processes that can be reproduced in different areas of knowledge of expected learning but with the constructivist approach to education outlined by the concept of General Systems Theory and the emphasis on humanism as a regulator of the emotions of human beings that intertwine in an educational community.

\section{Acknowledgments}

In the work carried out indirectly, the Continuous Training Unit in the state of Durango participated, since the call launched for the Diploma of System of Technical Attention to the School, where the project applied in the school zone was not configured. 10.

All teachers and students who were participating in this proposal were allowed to know a form of advice from the joint action of the entire community, in regard to the role that within each of the schools has the school principal to support the systematized work to impact in this case on the reading of compression from the area of literacy and the taste for the reading of discontinuous texts.

The distinction of the strengthening work of the revised texts, where the practice was linked to the theoretical support, as well as the generic and specific functions that outlined a work from the students, but with a willingness to speed up times dedicated to the academic field, with the willingness of teachers to increase their creative contributions, the reconciliation of clear ideas towards the type of advice and follow-up that is required from school supervisions.

\section{Conclusions}

It is considered important to extract from the actions defined from the identification of the objectives, the specific vision of where they wanted to influence, as well as the involvement of the students with the proposed activities, formulating the interaction directed towards the achievement of the learning of the communicative processes from reflection, from synthesis, literacy but from an approach to processing thinking skills, images, tastes, reflection and continuous texts.

Teachers are included from the level of recognition "Own cultures" that identifies each of them, as well as the school management that each educational center has from there, the introjection of the educational communities was achieved, looking for coincidences from the individuality.

The school supervision enhancing the management and accompaniment on the control to give adequate follow-up, depending on what the teacher is convinced to do, the helm carried by everyone turning the direction towards continuous improvement from a consignment of activities with precise elements and facilitating the processing of commitments.

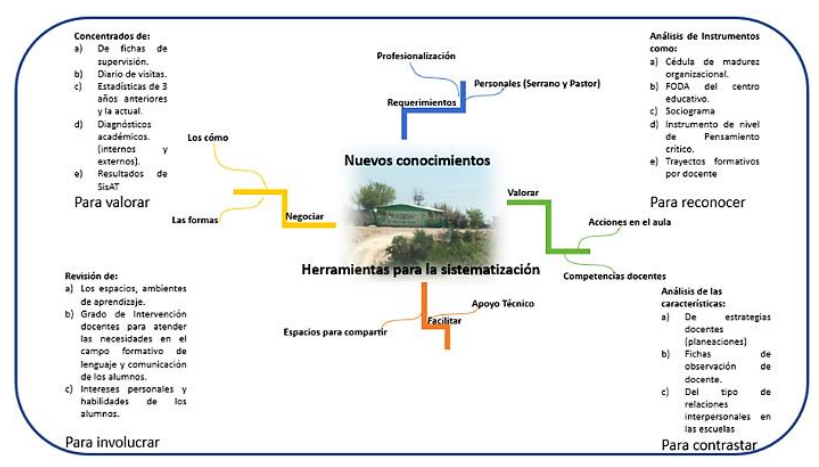

Figure 1

They allowed the improvement in three subjects of the current curricular network in basic education and the proposal that was developed from the foundation of the diagnosis of the school and teacher training. 


\section{References}

De la Peña, G., y Velaázquez, R. (2018) Algunas reflexiones sobre la teoría general de sistemas y el enfoque sistémico en las investigaciones científicas. Revista Cubana de Educación Superior. 2. P.p. 36

Proyecto (2019), Diccionario en línea: Real Academia de la Lengua Española. Recuperado de https://dle.rae.es/?w=involucrar\&m=form.

López Gumucio, Ricardo LA CALIDAD TOTAL EN LA EMPRESA MODERNA, PERSPECTIVAS. Vol. 8, núm. 2 (2005) pp. 6781 Universidad Católica Boliviana San Pablo Cochabamba, Bolivia.

Schmelkes, Sylvia HACIA UNA MEJOR CALIDAD DE NUESTRAS ESCUELAS. Secretaría de Educación Pública, pp 32, México, D.F. 2011

\author{
SEP, 2015, ESTRATEGIA \\ PARAINCREMENTAR Y ENRIQUECER LA \\ CAPACIDAD LECTORA, IEPSA, México, D.F. \\ pp 44 y 54
}

SEP, 2014, CUADERNO DEL SUPERVISOR, UNA SUPERVISIÓN EFECTIVA, PARA EL LOGRO DE LOS APRENDIZAJES DE LOS ALUMNOS, México, D.F. pp 78.

Schmelkes, Sivia, (1994) hacia una mejor calidad en nuestras escuelas, Biblioteca para la actualización del maestro. ISBN: 9682958687. México: Secretaría de Educación Pública, 1995.

Schön, D. (1982). El profesional reflexivo. Cómo piensan los profesionales cuando actúan. BA: Paidós

Vidal Ledo, María, \& Rivera Michelena, Natacha. (2007). Investigación-acción. Educación Médica Superior, 21(4)Recuperado en 03 de noviembre de 2019, de http://scielo.sld.cu/scielo.php?script=sci_arttext \&pid=S0864

$21412007000400012 \& \operatorname{lng}=$ es \& $\ln g=e s$.

Urraco, M., y Nogales, G. (2013). Michael Foucault: El funcionamiento de la institución escolar propio de la Modernidad. Andali (Revista Andaluza de Ciencias Sociales), 12,p.p.158. 